\title{
Radium-223 voor gemetastaseerd castratieresistent pros- taatcarcinoom: stand van zaken en toekomstperspectief
}

\author{
Dirk N. J. Wyndaele
}

Published online: 25 August 2020

(c) The Author(s) 2020

\begin{abstract}
Samenvatting Het arsenaal aan levensverlengende systemische behandelingen voor gemetastaseerd castratieresistent prostaatcarcinoom (mCRPC) is de afgelopen jaren uitgebreid met radium-223 (Ra-223), abirateron, enzalutamide en cabazitaxel. Ra-223 is sinds 2013 in de Europese Unie als Targeted alpha Therapy (TaT) geregistreerd voor de behandeling van patiënten met mCRPC met symptomatische botmetastasen. Recente aanbevelingen van een Europese expertgroep voor de optimale inzet van alle levensverlengende behandelopties voor mCRPC geven aan dat $\mathrm{Ra}-223$ een relevante optie is voor de tweede- en derdelijnsbehandeling na androgeenreceptorremmers en/of docetaxel. Dit overzichtsartikel vat deze aanbevelingen samen. Tevens wordt de praktijkervaring beschreven die de afgelopen jaren met Ra-223 is opgebouwd en wordt ingegaan op de belangrijkste recent voltooide en nog lopende klinische studies naar Ra223 in combinatie met docetaxel, androgeenreceptorremmers, immuunmodulerende antikankermiddelen of PARP-remmers. De mogelijk toekomstige toepassing van op PSMA gerichte radioligandtherapie bij prostaatkanker wordt kort uitgelicht.
\end{abstract}

Trefwoorden radium-223 - targeted alpha therapy gemetastaseerd castratieresistent prostaatcarcinoom . combinatiebehandeling $\cdot$ behandelingsvolgorde . radioligandtherapie

\section{Radium-223 in metastatic castration-resistant prostate cancer: current status and future perspectives}

Abstract In recent years, the armamentarium of life-prolonging systemic agents for metastatic castration-resistant prostaste cancer (mCRPC) has been expanded with radium-223 (Ra-223), abirateron, enzalutamide and cabazitaxel. Since 2013, Ra-223 is approved in the European Union as a Targeted alpha Therapy (TaT) for the treatment of patients with mCRPC and symptomatic bone metastases. Recently issued recommendations by a European expert group for the optimal usage of all life-prolonging treatment options for mCRPC position Ra-223 as a relevant option for second- and third-line treatment after androgen receptor inhibitors and/or docetaxel. This review paper summarizes these recommendations. It also describes real-world experience with Ra-223 accumulated in recent years and provides outlines of the most important recently completed or ongoing clinical trials of Ra-223 in combination with docetaxel, androgen receptor inhibitors, immunomodulatory anticancer agents or PARP inhibitors. The possible future application of PSMA-directed radioligand therapy in prostate cancer is briefly outlined.

Keywords Radium-223 - Targeted alpha therapy · Metastatic castration-resistant prostate cancer . Combination therapy · Treatment sequence · Radioligand therapy

\section{Introductie}

Radium-223 dichloride (Ra-223, Xofigo) is een alfastraling emitterende radionuclide dat zich specifiek richt op (osteoblastische) botmetastasen en daarom 
Tabel 1 Effectiviteit van Ra-223 bij mCRPC volgens real-world evidence en in de gerandomiseerde ALSYMPCA-studie [2, 7]

\begin{tabular}{|l|l|l|}
\hline Eindpunt & Ulitkomst & \\
\hline tijd tot eerste SSE (maanden, mediaan) & ROTOR-studie & ALSYMPCA \\
\hline zesmaands SSE-vrije overleving (\%) & niet bereikt & 16,6 \\
\hline totale overleving (maanden, mediaan) & 83 & 78 \\
\hline progressievrije overleving (maanden, mediaan) & 15,2 & 14,9 \\
\hline
\end{tabular}

ook wel wordt aangeduid als Targeted alpha Therapy (TaT).

Ra-223 is sinds 2013 als enige TaT in de Europese Unie geregistreerd voor de behandeling van gemetastaseerd castratieresistent prostaatkanker (mCRPC) met symptomatische botmetastasen [1]. Het bewijs voor de effectiviteit en veiligheid dat hieraan ten grondslag lag, is geleverd in de ALSYMPCA-studie, een gerandomiseerde placebogecontroleerde fase IIIstudie met patiënten met mCRPC en symptomatische skeletmetastasen, maar geen aangetoonde viscerale metastasen [2]. Deze studie toonde een significante overlevingswinst voor Ra-223, ongeacht of patiënten eerder docetaxel hadden gehad of niet [3]. De incidentie van bijwerkingen in de met Ra-223 behandelde groep was lager dan in de placebogroep [2]. Behandeling met Ra-223 was geassocieerd met een verbetering van de kwaliteit van leven in vergelijking met placebo [4].

Het beschikbaar komen van Ra-223 heeft een duidelijke impact gehad op de nucleaire geneeskunde. Het is voor nucleair geneeskundigen van belang het klinisch profiel van Ra-223 te kennen en - in multidisciplinair teamverband - mede te bepalen bij welke patiënten en in welke fase(n) van het totale behandeltraject Ra-223 effectief en veilig ingezet kan worden $[5,6]$.

\section{Ra-223 in de dagelijkse praktijk}

In de periode waarin de ALSYMPCA-studie werd uitgevoerd, hadden patiënten met mCRPC geen andere levensverlengende behandelopties dan chemotherapie met docetaxel. Behalve met Ra-223 is het arsenaal aan beschikbare middelen voor systemische toepassing de afgelopen jaren uitgebreid met het chemotherapeuticum cabazitaxel en de androgeenreceptorremmers abirateron en enzalutamide. Dit heeft ertoe geleid dat patiënten die de afgelopen jaren met Ra-223 zijn behandeld, in het algemeen intensiever voorbehandeld waren dan de deelnemers aan de ALSYMPCA-studie. In deze studie hadden 352 van de 614 patiënten $(57,3 \%)$ in de Ra-223 groep voor randomisatie docetaxel gekregen. Recentelijk is een analyse gepubliceerd van 300 patiënten uit 20 Nederlandse ziekenhuizen die buiten studieverband met Ra-223 zijn behandeld en in de prospectieve ROTOR-registratiestudie waren opgenomen [7]. In deze ROTOR-studie zijn het gebruik, de bijwerkingen en de effectiviteit van Ra-223 gerapporteerd in een reallife, niet-studie- gerelateerde mCRPC-patiëntenpopulatie. De gemiddelde leeftijd van de patiënten was 73,6 jaar, 90\% van de patiënten had meer dan zes botmetastasen. Een groot percentage was voorbehandeld met abirateron en/of enzalutamide $(80,5 \%)$, docetaxel $(74,1 \%)$ of cabazitaxel (19,5\%; steeds na voorafgaande behandeling met docetaxel). 11,3\% van de patiënten kreeg Ra-223 als eerstelijnsbehandeling; $34,7 \%$ had al één lijn systemische behandeling gehad, $32 \%$ ontving twee voorafgaande systemische behandelingen en $22 \%$ meer dan twee lijnen voorafgaand aan Ra-223. Bijna de helft van de patiënten $(46 \%)$ ontving de volledige kuur van zes injecties Ra-223, waarbij het mediane aantal vijf was. De primaire effectiviteitsparameter was het percentage patiënten dat na zes maanden vrij was van symptomatische skeletgerelateerde gebeurtenissen (zesmaands SSE-vrije overleving).

Na een mediane follow-up van 13,2 maanden bedroeg de zesmaands SSE-vrije overleving $83 \%$; de mediane tijd tot een eerste SSE was nog niet bereikt. De mediane progressievrije overleving (PFS) en de mediane totale overleving (OS) bedroegen respectievelijk 5,1 en 15,2 maanden. Een vergelijking van enkele eindpunten uit de hiervoor beschreven analyse met de overeenkomstige eindpunten uit de ALSYMPCAstudie leert dat de effectiviteit van Ra-223 in de Nederlandse praktijk in het post-ALSYMPCA tijdperk overeenkomt met die in de ALSYMPCA-populatie (tab. 1; $[2,7])$. Real-world evidence uit diverse landen met in totaal meer dan 3.500 behandelde patiënten bevestigen dat de mediane OS met Ra-223 (15,2-17,1 maanden) vergelijkbaar is met de OS in de ALSYMPCA-studie [2, 7-13].

De incidentie van bijwerkingen in de ROTOR-analyse was vergelijkbaar met die in de ALSYMPCA-studie $[2,7]$. Hematologische toxiciteit van graad 3 of 4 in de ROTOR-analyse betrof anemie (graad 3: 18,6\%), trombocytopenie (graad 3: 3,1\%; graad 4: $1 \%$ ) en neutropenie (graad 3: 2,4\%; graad 4: 0,3\%). De frequentst gerapporteerde niet-hematologische bijwerking was moeheid $(64,1 \%)$, in de meeste gevallen van graad 1-2 (55,5\%) [7].

\section{Herhaalde behandeling}

Recentelijk heeft de tweejaars-follow-up van een fase I-II-studie laten zien dat behandeling met een tweede serie van zes injecties Ra-223 goed verdragen wordt met minimale hematologische toxiciteit. Dit betrof een groep zorgvuldig geselecteerde patiënten die een 
Tabel 2 Klinische studies met combinaties op basis van Ra-223 bij mCRPC

\begin{tabular}{|l|l|l|l|}
\hline $\begin{array}{l}\text { Combinatiepartner } \\
\text { docetaxel }^{\mathrm{a}}\end{array}$ & $\begin{array}{l}\text { Studie-identificatie (acroniem) } \\
\text { NCT01106352 }\end{array}$ & Fase & Status \\
\hline docetaxel $^{\mathrm{a}}$ & NCT03574571 (DORA) & 3 & in uitvoering \\
\hline abirateron $^{\mathrm{a}}$ & NCT02043678 (ERA 223) & 3 & gerapporteerd 2019 \\
\hline enzalutamide & NCT02199197 & 2 & gerapporteerd 2020 \\
\hline enzalutamide & NCT02194842 (PEACE III) & 3 & in uitvoering, interim-rapportage 2019 \\
\hline niraparib & NCT03076203 & $1 \mathrm{~b}$ & in uitvoering \\
\hline olaparib & NCT03317392 & $1 / 2$ & in uitvoering \\
\hline atezolizumab & NCT02814669 & 1 & in uitvoering \\
\hline pembrolizumab & NCT03093428 & 2 & in uitvoering \\
\hline sipuleucel-T & NCT02463799 & 2 & in uitvoering \\
\hline aplus prednison/prednisolon & & \\
\hline
\end{tabular}

positieve response vertoonden op een eerdere behandeling met Ra-223. Deze patiënten met botmetastasen en adequate hematologische waarden hadden tussendoor geen chemotherapie hadden. De tweede serie injecties die door $66 \%$ van de patiënten werd voltooid, resulteerde in een rPFS (radiologische PFS vanaf de start van de tweede serie kuren) van 9,9 maanden, een SSE-vrije overleving van 12,8 maanden en een mediane OS van 24,4 maanden [14].

\section{Combinatietherapieën}

Ra-223 is dankzij de aangetoonde overlevingswinst, het gunstige veiligheidsprofiel en het positieve effect op de kwaliteit van leven potentieel aantrekkelijk voor toepassing in combinatie met andere levensverlengende behandelopties bij mCRPC-patiënten. Diverse klinische studies, waarvan een selectie is weergeven in tab. 2, zijn of worden uitgevoerd met een combinatie met Ra-223 [15]. Deze combinaties betreffen verschillende typen antikankermiddelen: chemotherapeutica, androgeenreceptorremmers, remmers van DNA damage response (DDR) pathways, PD-1/PD-L1immuuncheckpointremmers en een cellulaire immuuntherapie. De studies waarvan inmiddels resultaten gepubliceerd zijn, worden hierna uitgelicht. Voor uitgebreide reviews wordt verwezen naar recente overzichtsartikelen [16-18].

\section{Combinatie met docetaxel}

De uitkomsten van een eerstelijns fase I-IIa-studie van de combinatie van Ra-223 en docetaxel bij mCRPCpatiënten zijn in 2019 gepubliceerd [19]. Patiënten werden gerandomiseerd tussen docetaxelmonotherapie $\left(75 \mathrm{mg} / \mathrm{m}^{2}\right.$ iv $\left.\mathrm{q} 3 \mathrm{w} \mathrm{x} 10\right)$ of de combinatie van Ra-223 en docetaxel $\left(60 \mathrm{mg} / \mathrm{m}^{2}\right.$ iv $\left.\mathrm{q} 3 \mathrm{w} \times 10\right)$. Deze combinatiebehandeling bleek goed hanteerbaar qua veiligheid en resulteerde in langere onderdrukking van het PSA (mediane tijd tot PSA-progressie 6,6 maanden vs. 4,8 maanden, $p=0,020$ ) en botmarkers (alkalische fosfatase), en verbetering van de mediane PFS (12,0 maanden vs. 9,3 maanden, $p=0,566)$. Momenteel is de Amerikaans-Nederlandse DORA-studie
(NCT03574571) met de hiervoor genoemde combinatie in uitvoering. DORA is een gerandomiseerde fase III-studie waarin patiënten zijn geïncludeerd met mCRPC met minimaal twee botmetastasen, die in aanmerking komen voor behandeling met docetaxel; beperkte viscerale en kliermetastasen zijn toegestaan. De studie onderzoekt of de combinatie van Ra-223 en docetaxel tot een betere overleving leidt dan docetaxel alleen. Secundaire eindpunten zijn onder andere radiologische PFS, SSE-vrije overleving en kwaliteit van leven.

\section{Combinaties met androgeenreceptorremmers}

De ERA 223 fase III-studie met de combinatie van abirateron plus prednison en Ra-223 bij mCRPC is opgezet op basis van het feit dat beide middelen leiden tot verbeterde OS bij mCRPC en de werkingsmechanismen verschillend zijn. Bovendien werd deze combinatie (internationaal, bijvoorbeeld in de VS) in de praktijk reeds vaak gebruikt. Een retrospectieve analyse van data uit een early-access programma liet zien dat toevoeging van Ra-223 aan abirateron of enzalutamide een overlevingsvoordeel opleverde ten opzichte van Ra-223 alleen [20]. In de placebogecontroleerde ERA 223-studie werden asymptomatische en mild-symptomatische chemo-naïeve patiënten gerandomiseerd tussen abirateron met of zonder gelijktijdig Ra-223. De blindering van de studie werd voortijdig verbroken toen bleek dat het fractuurrisico in de combinatiegroep hoger was dan in de abiraterongroep [21]. Er was op dat moment geen verbetering in de SSE-vrije of totale overleving in de combinatiegroep. Deze resultaten hebben geleid tot aanpassing van de indicatiestelling voor Ra-223 door de EMA. Ra223 is sindsdien geïndiceerd als monotherapie of in combinatie met een LHRH-analoog voor volwassen patiënten met mCRPC, symptomatische botmetastasen en geen bekende viscerale metastasen, die progressief zijn na ten minste twee voorafgaande systemische therapielijnen voor mCRPC (andere dan LHRHanalogen) of die niet in aanmerking komen voor een beschikbare systemische mCRPC-behandeling [1]. De implicaties van deze indicaties voor de toepassing van 
Ra-223 in de praktijk worden geschetst in de paragraaf 'Aanwijzingen voor de praktijk'.

Een kleinschalige gerandomiseerde fase II-studie ( $n=39$ ) met de combinatie van Ra-223 en enzalutamide als tweedelijnsbehandeling na docetaxel heeft laten zien dat gelijktijdige behandeling met beide middelen veilig is, mits deze behandeling wordt gegeven in combinatie met botbeschermende middelen (bone health agents; BHA's). In geen van beide groepen werden pathologische fracturen gerapporteerd [22]. Op basis van gevonden botmetabolismemarkers en de PSA-respons concludeerden de auteurs dat de combinatie effectiever is dan enzalutamide alleen.

De PEACE III-studie is een lopende fase III-studie van de EORTC waarin de combinatie van enzalutamide en Ra-223 als eerstelijnsbehandeling van asymptomatische of licht-symptomatische (geen gebruik van opioïden; Brief Pain Inventory Score) patiënten met twee of meer botmetastasen, maar geen viscerale metastasen, wordt vergeleken met eerstelijnsbehandeling met enzalutamide alleen. Tussentijdse resultaten lieten zien dat aanvankelijk in deze studie het fractuurrisico in de combinatiegroep verhoogd was (33 vs. 13\%) [23]. Naar aanleiding van de hiervoor vermelde resultaten van de ERA 223-studie is in april 2018 in een protocolamendement vastgelegd dat alle patiënten in PEACE III ten minste zes weken voor de start van Ra-223 een continue behandeling met een BHA (zoledronaat of denosumab) moeten starten. Ook kunnen patiënten nu tot acht weken na de start van enzalutamide met Ra-223 starten in plaats van gelijktijdig. Sinds dit protocolamendement is doorgevoerd, is het fractuurrisico in zowel de enzalutamideals de combinatiegroep tot vrijwel nul gereduceerd [23].

\section{Combinaties met remmers van DDR pathways}

DDR pathways in de cel zijn verantwoordelijk voor de detectie en reparatie van DNA-schade. Ataxia telangiectasia mutated (ATM)- en ataxia telangiectasia and Rad3-related protein (ATR)-kinase en poly (ADPribose) polymerase (PARP) zijn belangrijke regulatoren in DDR pathways. Deze enzymen kunnen door het optreden van DNA-schade, zoals enkel- of dubbelstrengs DNA-breuken, geactiveerd worden. Het uitschakelen van deze enzymen met doelgerichte remmers resulteert in synthetische letaliteit, het onvermogen van cellen om de ontstane DNA-schade te repareren, met als gevolg apoptose. Omdat Ra-223 dubbelstrengs DNA-breuken en daardoor apoptose in doelwitcellen induceert, zou remming van sleutelenzymen van DDR pathways, zoals PARP, tumoren gevoeliger kunnen maken voor DNA-schade die wordt geïnduceerd door Ra-223. Deze hypothese wordt momenteel getest in fase I-II-studies waarin Ra-223 wordt gecombineerd met olaparib of niraparip (tab. 1). Diverse PARP-remmers zijn de afgelopen jaren geregistreerd voor de behandeling van BRCA-gemuteerd ovariumcarcinoom en mammacarcinoom [24-26].

Een retrospectief Nederlands-Amerikaans onderzoek met 93 mCRPC-patiënten heeft laten zien dat patiënten met gendefecten in elementen van de $D D R$ pathways (voornamelijk ATM, BRCA2, CDK12) die behandeld waren met Ra-223 een langere mediane OS hadden dan patiënten zonder zulke gendefecten (36,3 vs. 17,0 maanden; HR 2,29; $p=0,01$ ) [27]. Ook op de eindpunten 'tijd tot ALP-progressie' en 'tijd tot volgende systemische behandeling' leken patiënten met DDR pathway-defecten in het voordeel. Meer patiënten met DDR pathway-defecten voltooiden de behandeling met Ra-223 (79\% vs. 47\%; $p=0,05)$. Deze bevindingen geven een onderbouwing voor prospectief klinisch onderzoek van combinaties van Ra-223 met PARP- of ATR-remmers bij patiënten bij $D D R$ pathway-gendefecten.

\section{Combinaties met immunomodulerende middelen}

Verschillende onderzoeken wijzen op de mogelijkheid van systemische immunologische effecten van TaT, zoals bystander-effecten en andere off-target effecten, naast het lokale cytotoxische effect op botmetastasen [15]. In preklinisch onderzoek is gebleken dat combinaties van TaT en immuuntherapieën, zoals PD-1/PDL1 - of CTLA-4-checkpointremmers, een remmend effect hebben op metastasen die niet aan alfastraling zijn blootgesteld en op metastasering. Verder is aangetoond dat blootstelling aan subletale doses Ra-223 verschillende tumorcellijnen in vitro gevoeliger maakt voor immunogene celdood door cytotoxische T-lymfocyten. In een kleinschalig klinisch onderzoek werd bij mannen met mCRPC reeds na een eenmalige toediening van Ra-223 een afname van de hoeveelheid PD-1 positieve effector memory CD8 T-cellen in perifeer bloed gevonden [28]. Hoewel de immunologische betekenis van deze bevinding onduidelijk is, wijst ze op een systemisch effect van TaT op het immuunsysteem in de klinische setting.

Op basis van de hypothese dat TaT in patiënten een omgeving creëert waarin de effecten van immuuntherapie gepotentieerd kunnen worden, zijn klinische studies geïnitieerd waarin combinaties van Ra-223 en een PD-1/PD-L1-checkpointremmer (atezolizumab of pembrolizumab) of een autologe cellulaire immuuntherapie (sipuleucel-T) worden onderzocht (tab. 1). Atezolizumab en pembrolizumab zijn geregistreerd voor de behandeling van verschillende solide tumortypen [29, 30]. De oorspronkelijke Europese registratie van sipuleucel-T in Europa is enkele jaren geleden op verzoek van de fabrikant om commerciële redenen ingetrokken.

In Nederland loopt de DUOS-studie 'Radium223Insight', die gericht is op identificatie van voorspellende biomarkers voor Ra-223 bij mCRPC. De onderzoekers hopen dat op grond van de resultaten Ra-223 in de toekomst vroeger in het behandeltraject 
Figuur 1 Effect van Ra223 op tumorcellen en hun micro-omgeving in botweefsel. a Vicieuze cirkel van tumorgroei en abnormale botvorming. b Cytotoxische effecten op prostaatkankercellen, osteoblasten en osteoclasten [34]

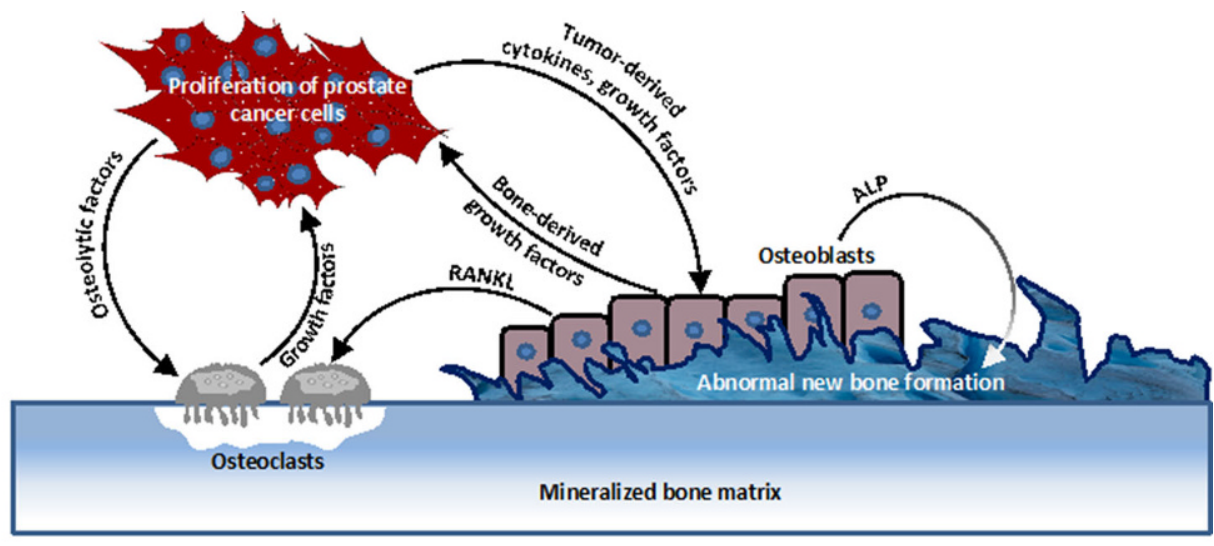

a

Adopted from Kingsley et al

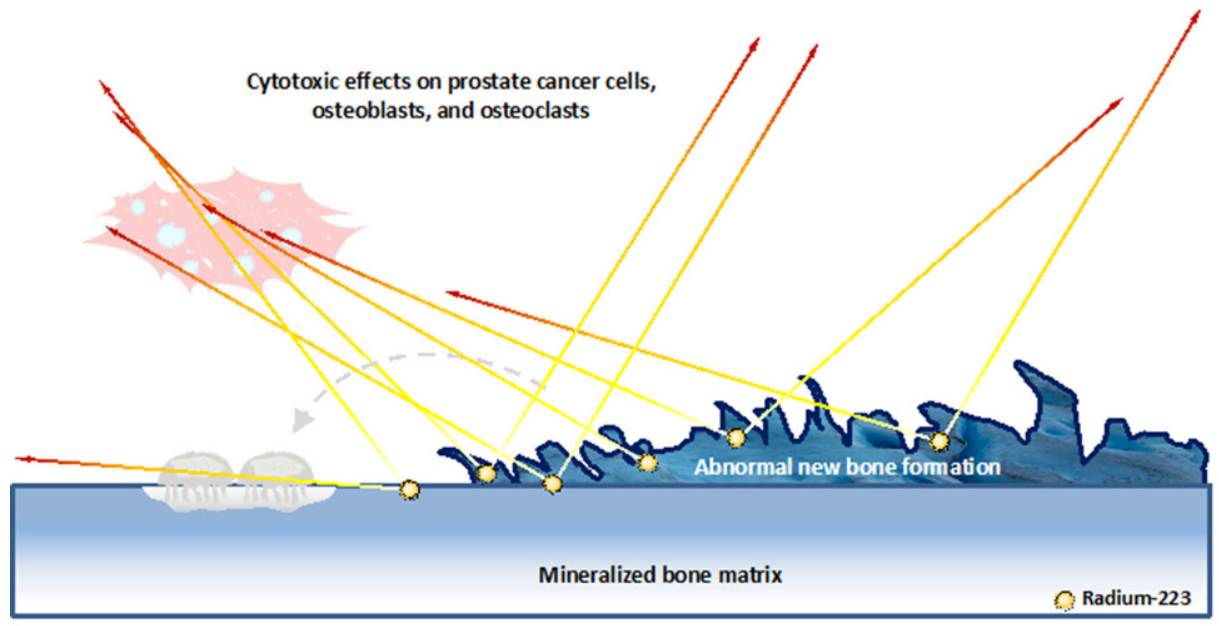

b van mCRPC ingezet zal kunnen worden. Een onderdeel van deze studie is de immuunrespons op Ra-223 te onderzoeken door middel van PD-L1-gelabelde PET-scans. Daarnaast kijkt men naar circulerende tumorcellen, circulerend tumor-DNA en immuuncellen in het bloed. In tumorbiopten wordt tumorDNA geanalyseerd en worden immunologische kleuringen uitgevoerd met het oog op mogelijke vervolgbehandelingen. Meer informatie is beschikbaar op de website van stichting DUOS (https://stichtingduos. $\mathrm{nl} /$ radium223insight-morpc-2de-lijn/).

\section{PSMA-radioligandtherapie}

Prostate-specific membrane antigen (PSMA) is een transmembraan-glycoproteïne dat sterk verhoogd tot expressie komt op het oppervlak van prostaatkankercellen, vooral bij gevorderd prostaatcarcinoom. Verschillende experimentele middelen die gericht zijn op PSMA bevatten verschillende radionucliden, waaronder de alfastralers actinium-225 en thorium-227 en de bètastraler lutetium-177 (Lu-177) [15, 31-33]. Het complex van Lu-177 en PSMA-617 (Lu-177-PSMA-617) wordt momenteel geëvalueerd in diverse klinische studies bij patiënten met gevorderd prostaatkanker, waaronder patiënten met mCRPC [32]. Er zijn nog geen gerandomiseerde studies die een overlevingswinst met Lu-177-PSMA-617 hebben aangetoond. Er zijn ook geen direct vergelijkende studies van Ra223 en Lu-177-PSMA-617 gerapporteerd. De VISIONstudie (NCT03511664) is de eerste gerandomiseerde fase III-studie van Lu-177-PSMA-617 vs. standard of care bij uitbehandelde patiënten met progressief mCRPC en bewezen PSMA-expressie. Het primaire eindpunt is OS. De eerste resultaten worden najaar 2020 verwacht.

Lu-177-PSMA-617 radioligandtherapie verschilt in radiologisch en biologisch opzicht op verschillende punten van TaT met Ra-223. Allereerst is Lu-177PSMA-617 een bètastraler terwijl Ra-223 alfastraling genereert die een hogere lineaire energieoverdracht over kortere afstand genereert dan bètastraling. Dit leidt tot dubbelstrengs DNA-breuken in een hoge frequentie in naastgelegen tumorcellen, wat resulteert in het cytotoxische effect van Ra-223. Bèta-emitters induceren voornamelijk enkelstrengs DNA-breuken. Na binding van Lu-177-PSMA-617 aan het PSMA op de tumorcel wordt het Lu-177-bevattende complex geïnternaliseerd, waarna dit in de cel zijn bètastraling aflevert wat tot DNA-schade en apoptose leidt. Ra-223 


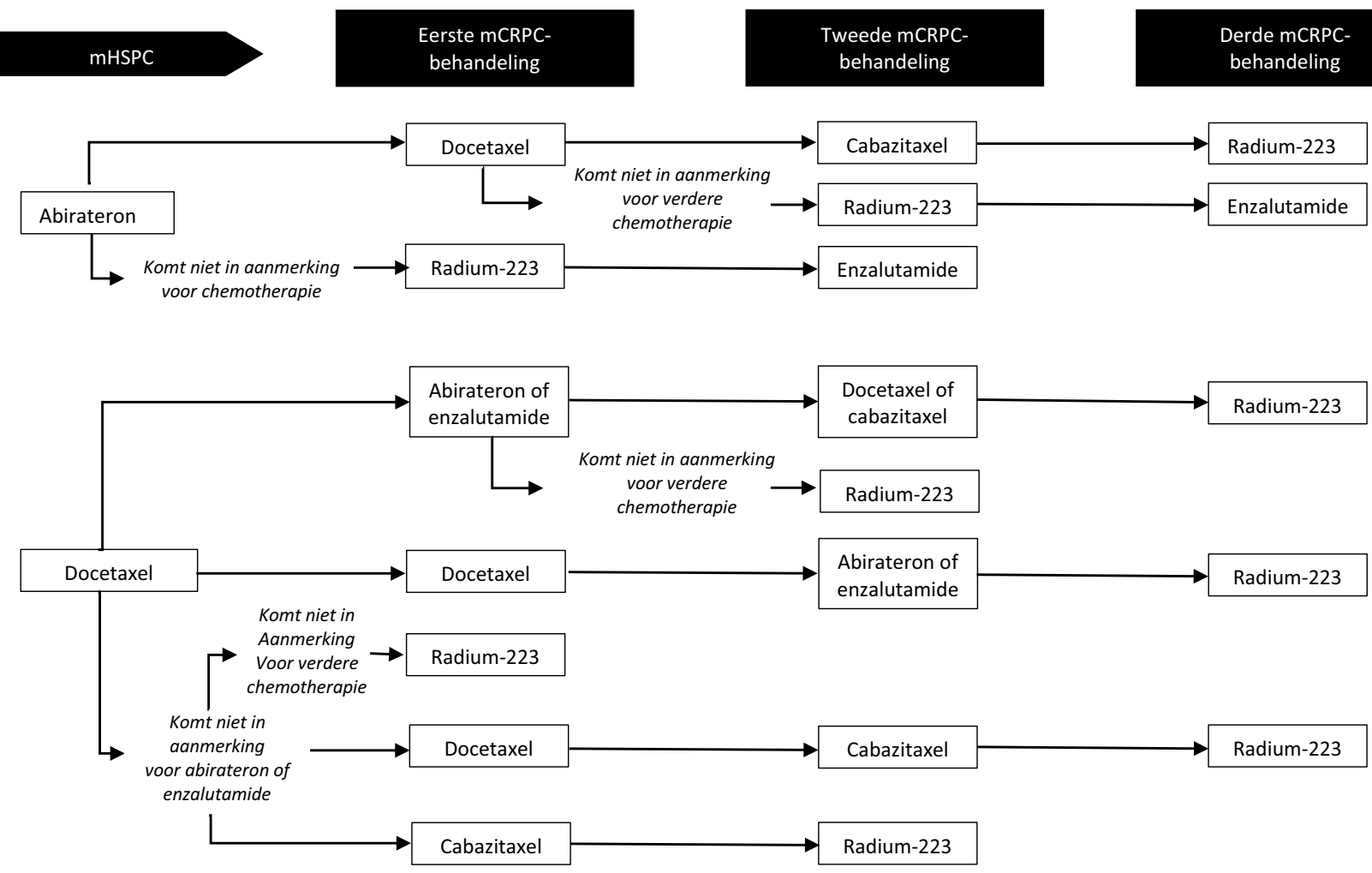

mHSPC: gemetastaseerd hormoongevoelig prostaatcarcinoom mCRPC: gemetastaseerd castratieresistent prostaatcarcinoom

Figuur 2 Aanbevelingen voor de sequentiële inzet van behandelopties bij mCRPC. (Bewerkt naar O’Sullivan et al. [16])

heeft een tweevoudig werkingsmechanisme. Naast inductie van tumorceldood heeft het additionele effecten op de tumormicro-omgeving en doorbreekt het de vicieuze cirkel van tumorgroei en abnormale botvorming (fig. 1; [34]). De halfwaardetijd van Ra-223 (11,4 dagen) is langer dan die van Lu-177 (6,4 dagen). Er is een wezenlijk verschil in targeting-mechanisme tussen Ra-223 en Lu-177-PSMA-617. Ra-223 bindt zich als analogon van calcium aan hydroxyapatiet in nieuw gevormd botweefsel. Het accumuleert hierdoor specifiek op locaties met verhoogde botombouw, zoals botmetastasen van solide tumoren. De targeting van Lu-177-PSMA-617 berust op verhoogde cellulaire expressie van PSMA door prostaatkankercellen, ongeacht hun lokalisatie.

\section{Aanwijzingen voor de praktijk}

Een groep Europese experts, bestaande uit urologen, medisch-oncologen en radiotherapeuten, heeft naar aanleiding van de resultaten van de ERA 223-combinatiestudie aanbevelingen geformuleerd voor de toepassing van Ra-223 in het veranderende landschap van de mCRPC-behandeling [16]. De nadruk ligt op botbeschermende maatregelen en de optimale volg- orde bij het inzetten van de beschikbare levensverlengende behandelingen.

De expertgroep raadt aan om voldoende aandacht te schenken aan de botgezondheid van patiënten met prostaatkanker en reeds bij de start van androgeendeprivatie (ADT) de botmineraaldichtheid te evalueren en verder te monitoren. Patiënten die ADT krijgen, dient geadviseerd te worden calcium en vitamine D-supplementen te gebruiken. Bij de patiënten die osteopenie ontwikkelen, dient gestart te worden met BHA's om osteoporose te voorkomen of te behandelen. Als zich castratieresistentie heeft ontwikkeld, dient bij patiënten die in deze fase botmetastasen hebben, behandeling met BHA's gestart te worden, ongeacht de aard van de systemische antikankerbehandeling.

Ten aanzien van Ra-223 in het post-ALSYMPCAtijdperk, met meer levensverlengende behandelopties dan voorheen, constateert de expertgroep, mede op basis van real-world evidence, dat Ra-223 bij mCRPC nog steeds een relevante optie is. Zij adviseert Ra223 zo vroeg mogelijk in het ziekteproces in te zetten, voordat zich viscerale metastasen manifesteren, zodat Ra-223 als levensverlengende, weinig toxische behandeling niet onbenut blijft. Bij de beoordeling of een patiënt in aanmerking komt voor Ra-223 dient 
gekeken te worden naar de respons op voorafgaande behandelingen, het wel of niet in aanmerking komen voor chemotherapie of antihormonale therapieën, de voorkeur van de patiënt en of de patiënt de volle zes kuren Ra-223 zal kunnen voltooien.

Er zijn geen data waarop de optimale volgorde van de verschillende behandelopties voor mCRPC eenduidig gebaseerd kan worden. Daarom heeft de expertgroep verschillende scenario's uitgewerkt die de plaats van Ra-223 bij gevorderde prostaatkanker aangeven, gebaseerd op de vigerende EMA-indicatiestelling voor Ra-223 [1], resultaten van klinisch onderzoek en realworld evidence. Men onderscheidt twee populaties patiënten met mCRPC die in aanmerking komen voor Ra-223. De eerste groep wordt gevormd door patiënten die al twee voorafgaande systemische behandelingen voor mCRPC hebben gehad en nog baat kunnen hebben bij Ra-223. De tweede groep bestaat uit patiënten die geen andere systemische behandeling kunnen of willen ondergaan, bijvoorbeeld als gevolg van de ineffectiviteit van twee opeenvolgende antihormonale therapieën, comorbiditeit, fragiliteit, of voorkeur van de patiënt. Een van de drie geschetste scenario's gaat uit van patiënten met gemetastaseerd hormoongevoelig prostaatcarcinoom (mHSPC) die progressie hebben naar $\mathrm{MCRPC}$ en reeds in de fase van mHSPC met androgeendeprivatie plus abirateron of docetaxel waren behandeld (fig. 2). Dit scenario heeft de afgelopen jaren aan relevantie gewonnen nadat in klinische studies was aangetoond dat het naar voren halen van androgeenreceptorremmers of docetaxel in het ziekteproces bij prostaatkanker geassocieerd was met betere uitkomsten [35]. De expertgroep heeft soortgelijke scenario's beschreven voor patiënten die in de fase van mHSPC of niet-gemetastaseerd castratieresistent prostaatcarcinoom (nmCRPC) met ADT werden behandeld of in de fase van nmCRPC met enzalutamide, apalutamide of darolutamide (niet weergegeven).

In de aanbevelingen van de Europese expertgroep heeft Ra-223 voornamelijk een plaats als systemische tweede- en derdelijnsbehandeling van mCRPC na een androgeenreceptorremmer en/of docetaxel. Data uit de eerder genoemde ROTOR-studie hebben laten zien dat in de Nederlandse praktijk aanzienlijke percentages patiënten Ra-223 als tweedelijns- $(34,7 \%)$ of derdelijns- $(32,0 \%)$ behandeling kregen [7]. Het is dus aannemelijk dat Ra-223 ook in de huidige praktijk een belangrijke bijdrage kan leveren aan de totale behandelstrategie bij patiënten met botdominante mCRPC.

\section{Conclusies}

Internationale real-world evidence bevestigt de effectiviteit van TaT met Ra-223 als levensverlengende optie bij patiënten met mCRPC en symptomatische botmetastasen in het post-ALSYMPCA tijdperk. Lopend klinisch onderzoek van Ra-223 in combinatie met chemotherapie (docetaxel,) androgeenreceptor- remmers, DDR pathway-remmers of $\mathrm{PD}-1 / \mathrm{PD}-\mathrm{L} 1$ checkpointremmers zal leren of deze combinaties een therapeutische meerwaarde hebben in de setting van MCRPC.

Financiering Publicatie van dit artikel is mede mogelijk gemaakt door financiële ondersteuning van Bayer.

Conflicts of interest D. N. J. Wyndaele heeft geen conflicts of interest te melden bij dit artikel.

Open Access This article is distributed under the terms of the Creative Commons Attribution 4.0 International License (http://creativecommons.org/licenses/by/4.0/), which permits unrestricted use, distribution, and reproduction in any medium, provided you give appropriate credit to the original author(s) and the source, provide a link to the Creative Commons license, and indicate if changes were made.

\section{Literatuur}

1. Xofigo (radium-223 Ra-223 dichloride). Samenvatting van de productkenmerken update 18 mei 2020. Beschikbaar via https://www.ema.europa.eu/en/documents/ product-information/xofigo-epar-product-information nl.pdf. Geraadpleegd 25 juli 2020.

2. Parker C, Nilsson S, Heinrich D, et al. Alpha emitter radium223 and survival in metastatic prostate cancer. New Engl J Med. 2013;369:213-23.

3. Hoskin P, Sartor O, O'Sullivan JM, et al. Efficacy and safety of radium-223 dichloride in patients with castration-resistant prostate cancer and symptomatic bone metastases, with or without previous docetaxel use: a prespecified subgroup analysis from the randomised, double-blind, phase $3 \mathrm{AL}-$ SYMPCA trial. Lancet Oncol. 2014;15:1397-406.

4. Parker C, Coleman RE, Vogelzang N, et al. Updated survival, quality of life (QOL), and safety data of radium-223 chloride (RA-223) in patients with castration-resistant prostate cancer (CRPC) with bone metastases from the phase 3 doubleblind, randomized, multinational study (ALSYMPCA). Ann Oncol. 2012;23(Suppl9):ix296.

5. Oyen W, Sundram F, Haug AR, et al. Radium-223 Dichloride (Ra-223) for the Treatment of Metastatic Castrationresistant Prostate Cancer: Optimizing Clinical Practice in Nuclear Medicine Centers. J Clin Oncopathol. 2015;3:1-25.

6. Wyndaele DNJ, Voort R van der, Koldewijn EL, Warmerdam LJC van. Radium-223 dichloride in the treatment of metastatic prostate cancer. Tijdschr Nucl Geneesk. 2016;38(4):1655-9.

7. Badrising SK, Louhanepessy RD, Noort V van der, et al. A prospective observational registry evaluating clinical outcomes of Radium-223 treatment in a nonstudy population. Int JCancer. 2020;147(4):1143-51.

8. HiganoCS, TombalB, Miller K, SaadF, etal. Clinical outcome with radium-223. Ra.22(3):. in patients (pts) previously treated with abiraterone (Abi) or enzalutamide (Enza): a retrospective study using real-world (RW) data from pts with metastatic castration-resistant prostate cancer (mCRPC). Ann Oncol. 2018;29(suppl_8):viii288. https:// doi.org/10.1093/annonc/mdy284.036.

9. Miller K, Heinrich D, O'Sullivan JM, et al. Radium-223 (Ra-223) therapy after abiraterone (Abi): analysis of symptomatic skeletal events (SSEs) in an international early access program (iEAP) in patients (pts) with metastatic castration-resistant prostate cancer (mCRPC). Ann Oncol. 2018;29(suppl_8):viii287. 
10. Schrijvers D, Jamar F, Goffin K, et al. Overall survival in mCRPC patients treated with radium 223in real life clinical practice in Belgium. Global Congress of Prostate Cancers (PROSCA). October, Band 2019. Brussels, Belgium: poster; pag. 23-4.

11. Petersen DSPM. Essler M, et al. Interim analysis of the REASSURE (Radium-223 alpha Emitter Agent in non-intervention Safety Study in mCRPC popUlation for longteRm Evaluation) study: patient characteristics and safety according to prior use of chemotherapy in routine clinical practice. Eur J Nucl Med Mol Imaging. 2019;46:1102-10.

12. George DJ, Sternberg CN, Sartor AO, et al. Clinical outcome with concurrent or layered treatment with radium-223 and abiraterone: A retrospective study of realworld experience with patients (pts) with metastatic castration-resistant prostate cancer (mCRPC). J Clin Oncol. 2019;37(7_suppl):253-3.

13. Heidenreich A, Gillessen S, Heinrich D, et al. Radium-223 in asymptomatic patients with castration-resistant prostate cancer and bone metastases treated in an international early access program. Bmc Cancer. 2019;19(1):12.

14. Sartor O, Heinrich D, Mariados N, et al. Re-treatment with radium-223: 2-year follow-up from an international, open-label, phase $1 / 2$ study in patients with castrationresistant prostate cancer and bone metastases. Prostate. 2019;79:1683-91.

15. De Vincentis G, Gerritsen W, Gschwend JE, et al. Advances in targeted alpha therapy for prostate cancer. Ann Oncol. 2019;30:1728-39.

16. O'Sullivan JM, Carles J, Cathomas R, et al. Radium223 Within the evolving treatment options for metastatic castration-resistant prostate cancer: Recommendations from a European Expert Working Group. Eur Urol Oncol. 2019;S2588-9311(19)30031-8. https://doi.org/10.1016/j. euo.2019.02.007. Online ahead of print.

17. Morris MJ, CoreyE, Guise TA, et al. Radium-223 mechanism of action: implications for use in treatment combinations. Nat Rev Urol. 2019;16:745-56.

18. Smits M, Gerritsen W, Mehra N. Future therapeutic strategies for metastatic prostate cancer. Tijdschr Urol. 2019;9:117-30.

19. Morris MJ, Loriot Y, Sweeney CJ, et al. Radium-223 in combination with docetaxel in patients with castrationresistant prostate cancer and bone metastases: a phase 1 dose escalation/randomised phase $2 \mathrm{a}$ trial. Eur J Cancer. 2019;114:107-16

20. Saad F, Carles J, Gillessen S, et al. Radium-223 and concomitant therapies in patients with metastatic castrationresistant prostate cancer: an international, early access, open-label, single-arm phase $3 \mathrm{~b}$ trial. Lancet Oncol. 2016;17:1306-16.

21. Smith M, Parker C, Saad F, et al. Addition of radium223 to abiraterone acetate and prednisone or prednisolone in patients with castration-resistant prostate cancer and bone metastases (ERA 223): a randomised, doubleblind, placebo-controlled, phase 3 trial. Lancet Oncol. 2019;20:408-19.

22. Agarwal N, Nussenzveig R, Hahn AW, et al. Prospective evaluation of bone metabolic markers as surrogate markers of response to radium-223 therapy in metasta- tic castration-resistant prostate cancer. Clin Cancer Res. 2020;26(9):2104-10.

23. Tombal BF, Loriot Y, Saad F, et al. Decreased fracture rate by mandating bone-protecting agents in the EORTC 1333/ PEACE III trial comparing enzalutamide and Ra223 versus enzalutamide alone: An interim safety analysis. J Clin Oncol.2019;37(15_suppl):5007-7.

24. Lynparza. Samenvatting van de productkenmerken update 28 mei 2020. Beschikbaar via https://www.ema.europa. eu/en/documents/product-information/lynparza-eparproduct-information_nl.pdf. Geraadpleegd 25 juli 2020.

25. Zejula. Samenvatting van de productkenmerken update 10 juni 2020. Beschikbaar via https://www.ema. europa.eu/en/documents/product-information/zejulaepar-product-information_nl.pdf. Geraadpleegd 25 juli 2020.

26. Rubraca. Samenvatting van de productkenmerken update 25 mei 2019. Beschikbaar via https://www.ema.europa. $\mathrm{eu} / \mathrm{en} /$ documents/product-information/rubraca-eparproduct-information_nl.pdf. Geraadpleegd 25 juli 2020.

27. van der Doelen MJ, Isaacsson Velho P, Slootbeek PHJ, et al. Overall survival using radium-223 (Ra223) in metastatic castrate-resistant prostate cancer (mCRPC) patients with and without DNA damage repair (DDR) defects. J Clin Oncol.2020;38(6_suppl):121-1.

28. Kim JW, Shin MS, Kang Y, Kang I, Petrylak DP. Immune analysis of radium-223 in patients with metastatic prostate cancer. Clin Genitourin Cancer. 2018;16:e469-76.

29. Tecentriq. Samenvattingvan deproductkenmerken update 13 juli 2020. Beschikbaar via https://www.ema.europa. eu/en/documents/product-information/tecentriq-eparproduct-information_nl.pdf. Geraadpleegd 25juli 2020.

30. Keytruda. Samenvatting van de productkenmerken update 18 juni 2020. Beschikbaar via https://www.ema.europa. eu/en/documents/product-information/keytruda-eparproduct-information_nl.pdf. Geraadpleegd op 25juli 2020.

31. Emmett L, Willowson K, Violet J, Shin J, Blanksby A, Lee J. Lutetium 177 PSMA radionuclide therapy for men with prostate cancer: a review of the current literature and discussion of practical aspects of therapy. J Med Radiat Sci. 2017;64(1):52-60.

32. Vis AN, Jansen BHE, Bodar YJL. et al. 177Lutetium PSMAradioligandtherapie bij prostaatkanker. Tijdschr Urol. 2020. https://doi.org/10.1007/s13629-019-00275-6.

33. Hammer S, Hagemann UB, Zitzmann-Kolbe S, et al. Preclinical efficacy of a PSMA-targeted thorium-227 conjugate (PSMA-TTC), a targeted alpha therapy for prostate cancer. Clin Cancer Res. 2020;26(8):1985-96.

34. Suominen MI, Fagerlund KM, RissanenJP, etal. Radium-223 inhibits osseous prostate cancer growth by dual targeting of cancer cells and bone microenvironment in mouse models. Clin Cancer Res. 2017;23:4335-46.

35. Hird AE, Magee DE, Bhindi B, et al. A systematic review and network meta-analysis of novel androgen receptor inhibitors in non-metastatic castration-resistant prostate cancer. Clin Genitourin Cancer. 2020;S1558-7673(20)30039-2. https://doi.org/10.1016/j.clgc.2020.02.005. Online ahead of print.

drs. Dirk N.J. Wyndaele, nucleair geneeskundige 


\title{
Hier staat een advertentie.
}

\author{
cef bohn \\ stafleu \\ van loghum
}

Houten 2020 


\title{
Hier staat een advertentie.
}

\author{
cef bohn \\ stafleu \\ van loghum
}

Houten 2020 